\title{
ERRATUM
}

David Burgner $\cdot$ Stanley Usen $\cdot$ Kirk Rockett

Muminatou Jallow $\cdot$ Hans Ackerman

Alessandra Cervino $\cdot$ Margaret Pinder

Dominic P. Kwiatkowski

\section{Nucleotide and haplotypic diversity of the NOS2A promoter region and its relationship to cerebral malaria}

Published online: 20 January 2004

(C) Springer-Verlag 2004

\section{Hum Genet (2003) 112:379-386}

In the above paper the correct allele of the $-2447 \mathrm{SNP}$ in haplotype Gam4 (Table 2) is $-2447 \mathrm{G}$ and not $-2447 \mathrm{C}$. The authors apologise for the error.

The online version of the original article can be found at http://dx.doi.org/10.1007/s00439-002-0882-4

D. Burgner · K. Rockett · H. Ackerman - A. Cervino

D. P. Kwiatkowski (汭)

Wellcome Trust Centre for Human Genetics,

University of Oxford, Roosevelt Drive, Oxford, OX2 7BN, UK

Tel.: +44-1865-287654, Fax: +44-1865-287533,

e-mail: dominic.kwiatkowski@paediatrics.ox.ac.uk

S. Usen $\cdot$ M. Jallow $\cdot$ M. Pinder

Medical Research Council Laboratories, Fajara, The Gambia

M. Jallow

Royal Victoria Hospital, Banjul, The Gambia 